\title{
Economics of a reduction in smoking: case study from Heartbeat Wales
}

\author{
Ceri J Phillips, Malcolm J Prowle
}

\begin{abstract}
Study objective-This study aims to apply economic principles and techniques in evaluating a health promotion programme.

Design-This study is an economic appraisal of the Heartbeat Wales no smoking intervention programme. The costs incurred over the four year period 1985-89 have been identified and estimates have been made of the likely future impact of the reduced smoking prevalence within Wales in terms of reduced morbidity and displaced mortality in three disease groups-coronary heart disease, lung cancer, and chronic bronchitis.

Setting-Wales, UK.

Results-The net present value of benefits is considerably greater than costs in terms of both the NHS and the economy as a whole in Wales. In addition, the net costs per life year saved shows that the programme generates additional working life years at relatively low cost. Because not all the benefits can be fully attributed to the programme 'impact rates' ranging from 100 to $10 \%$ have been applied to the level of benefits. The evidence suggests that even if only $10 \%$ of the benefits could be attributed to the programme there is still a positive net present value of benefits. The relative efficiency of this programme has not been considered here.

Conclusion-Large scale benefits to the NHS and the economy as a whole can be derived from reductions in smoking.
\end{abstract}

f Epidemiol Community Health 1993; 47: 215-223

As setting priorities and allocating resources become more evident within the NHS and governments seek to reorientate policies towards health and a healthy life, more attention should be paid to the economic evaluation of preventive measures within health care. As Jones and Baker have stated, 'budget holders have a responsibility to ensure that the money is being spent with maximum benefit and efficiency'. ${ }^{1}$ To date, however, little attention has been paid to the economic evaluation of programmes designed to change behaviour patterns, partly because of the less direct relationship between behaviour and disease and partly because of the time lags between behaviour change and subsequent disease reduction. Cribb and $\mathrm{Haycox}^{2}$ highlighted the fact that cost effectiveness analysis in health promotion is difficult because of the complexities involved in estimating the true final output of health promotion, while Engleman and Forbes ${ }^{3}$ stated that economic aspects of health education had received inadequate attention to date and suggested an economic framework for discussing health education. The latter explained the absence of successful applications of costbenefit techniques to health education programmes by, 'the lack of effectiveness data of the type necessary for cost-benefit analyses'.

This study aims to assess the costs and benefits of a health promotion programme designed to reduce the prevalence of smoking - a reduction that is a central strategy for cutting heart disease and 'all cause' mortality. Smoking alone is estimated to double the risk of coronary heart disease. Smoking combined with one of the other two primary risk factors, hypertension and hypercholesterolaemia quadruples the risks, and if smoking is combined with both of these primary risk factors, the risks are eightfold. There are two broad strategies for reducing smoking prevalence-those designed to discourage young people from starting and those to encourage existing smokers to quit. Within these broad strategies there is a range of methods that can and has been used to achieve the goal. ${ }^{4}$

The intervention considered in this study is that undertaken as part of the Heartbeat Wales (HBW) programme, which included in its planning document the target of reducing smoking prevalence within Wales by $1 \%$ per year for the first five years. ${ }^{6}$ This target was achieved with a decline of $4 \cdot 1 \%$ in men and $2 \cdot 7 \%$ in women between 1985 and 1988 .

The HBW programme, initiated in April 1985 as the national (UK) demonstration project for reducing coronary heart disease, has employed a multifaceted approach, focusing on the major risk factors such as smoking, physical inactivity, and poor nutrition, and involving numerous groups such as local authorities, commerce, industry, and the voluntary sector. This study is concerned specifically with the no smoking intervention of the HBW programme during the period 1985-88. Smoking prevalence in Wales was measured by population surveys in 1985 and 1988 involving 22000 and 8000 subjects, respectively. Table I shows that there was an overall decline in smoking of $4.1 \%$ in men and $2.7 \%$ in women. Thus, the target of reducing prevalence by $1 \%$ per year was exceeded in men and almost achieved in women. Smoking declined in men and women of all ages, with the most noticeable reduction in 35-44 year olds, $(-5 \%$ men, $-7 \%$ women $)$. All social groups showed a decline except for the small rise is prevalence in households in which the head was unemployed at the time of the survey.

\section{Methods}

The HBW no smoking intervention was appraised in two ways: 
(1) Health service appraisal. The costs to the Health Promotion Authority for Wales and district health authorities, and benefits attibutable to the health service in Wales through reduced morbidity and displaced mortality as a consequence of the HBW no smoking intervention were estimated.

(2) Economic appraisal. The full resource costs and benefits across all sectors of Welsh society attributable to the no smoking intervention (that is the costs and benefits included in the health service appraisal plus the costs to industry and commerce and the benefits accruing from a reduction in lost output from displaced mortality and reduced morbidity were determined.

In addition to the general lack of effectiveness data with which to undertake economic evaluations of preventive health care schemes there are a number of other methodological issues highlighted by other studies ${ }^{378}$ that need to be addressed at this stage.

\section{HEALTH VERSUS TAXATION VERSUS}

ADVERTISING

Ideally, it would be possible to compare the outcomes of the HBW programme generated as a result of the reduction in smoking in Wales with a range of alternative approaches to securing a reduction in smoking prevalence (such as fiscal measures and curtailment of advertising) or to compare the extent of the reduction in smoking prevalence in Wales with that in a comparative area within the same time period, or both. In seeking to undertake the former comparison we were restricted by current government policy relating to taxation and advertising of tobacco products. We had to rely therefore on previous work in the area. For example, Townsend ${ }^{9}$ has suggested that while the anti-smoking publicity has reduced smoking prevalence in the higher social classes, it has had little impact on lower social classes. She proposed that increasing the tax on cigarettes to the mid-1960s or post war levels would reduce smoking prevalence, cigarette tax payments, and smoking related mortality in lower social classes to the lower levels of social classes 1 and 2. Furthermore, she stated that increasing cigarette prices by $20 \%$, continuing health

Table I Percentage of current smokers by age, sex and social class in Wales (1985 and 1988)

\begin{tabular}{llll}
\hline Age $(y)$ & Sex & $\begin{array}{l}1985 \\
(\%)\end{array}$ & $\begin{array}{l}1988 \\
(\%)\end{array}$ \\
\hline $18-24$ & Men & $34 \cdot 9$ & $30 \cdot 9$ \\
& Women & $32 \cdot 4$ & $30 \cdot 9$ \\
$25-34$ & Men & $41 \cdot 6$ & $38 \cdot 0$ \\
& Women & $35 \cdot 3$ & $34 \cdot 4$ \\
$35-44$ & Men & $45 \cdot 7$ & $40 \cdot 7$ \\
& Women & $37 \cdot 0$ & $30 \cdot 5$ \\
$45-54$ & Men & $43 \cdot 0$ & $40 \cdot 5$ \\
& Women & $32 \cdot 6$ & $29 \cdot 6$ \\
$55-64$ & Men & $39 \cdot 4$ & $35 \cdot 3$ \\
& Women & $29 \cdot 0$ & $27 \cdot 3$ \\
Total & & & \\
18-64 & & $41 \cdot 2$ & $37 \cdot 1$ \\
& Men & $33 \cdot 4$ & $30 \cdot 7$ \\
Social group & Women & & \\
I & & & \\
II & & $22 \cdot 5$ & $18 \cdot 5$ \\
IIIN & & $30 \cdot 0$ & $23 \cdot 6$ \\
IIIM & & $32 \cdot 5$ & $27 \cdot 8$ \\
IV & & $39 \cdot 0$ & $35 \cdot 5$ \\
V & & $42 \cdot 5$ & $37 \cdot 4$ \\
Economically inactive & & $49 \cdot 5$ & $45 \cdot 0$ \\
& & $44 \cdot 5$ & $42 \cdot 8$ \\
Total & & $37 \cdot 0$ & $33 \cdot 4$ \\
All unemployed & & $49 \cdot 5$ & $52 \cdot 4$ \\
Long term unemployed & & $53 \cdot 5$ & $54 \cdot 5$ \\
\hline
\end{tabular}

education, and curtailing of cigarette advertising, could reduced smoking by $20 \%$ without affecting the government's revenue. Maynard, ${ }^{10}$ however, suggested that the fall in tobacco consumption was a result of health promotion rather than tax. $\mathrm{He}$ argued that in health promotion in relation to addictive substances, policy making needs to be illuminated by careful economic evaluation, with the cost-benefit trade offs being made explicit.

\section{SPILLOVER EFFECTS}

When making comparison between smoking prevalence in Wales and another area over the period, it is virtually impossible to avoid 'spillover effects' into the comparison area, since many of the HBW initiatives have been undertaken in other schemes. The reductions in smoking prevalence in Wales were greater, however, during the period than in England. This study therefore has as its alternative that of 'doing nothing', recognising that tastes relating to smoking are continually changing and attempting to compensate for this deficiency by using a series of 'impact rates' to describe the effects of the HBW programme.

DOES PREVENTION LEAD TO ADDITIONAL COSTS

The second area concerns the notion of spillover effects into other sectors of the health service or the economy as a whole. There is much debate about whether the 'success' of preventive measures leads to additional health care costs in the future. ${ }^{112} \mathrm{We}$ believe that the magnitude of these costs is unlikely to be significant, given the effects of discounting ${ }^{7}$ and the fact that improvements in lifestyle achieved through a reduction in smoking prevalence can reduce levels of disease and disability among the elderly, thereby reducing their demands on the health service. There are also, what may be termed potential negative benefits, resulting from such a programme. For example, the tobacco industry may well be forced to cut its production levels and lay off employees as a result of a fall in cigarette consumption. Similarly, there will be a reduction in the excise duty entering the exchequer as a result of a reduction in consumption of tobacco and there may be implications for social security and pension payments as people live longer. While the existence of these spillover effects into other sectors of the UK economy is recognised, however, this study is concerned with policy within Wales rather than the UK as a whole.

\section{DEFINING BENEFITS}

The third area concerns the range of benefits to be included in the appraisal. This study considers the impact of reduced morbidity and displaced mortality on resource use and productive output. It also uses the number of life years saved as an alternative outcome measure to arrive at the net cost per life year saved. The former approach can be justified by reference to the magnitude of working life years lost as a result of smoking related deaths and the working days lost through sickness attributed to smoking. One of the main arguments for the inclusion of 'production gains or losses' is the importance attatched to them by the community. 'Other things being equal we would prefer a health treatment that removed a patient from the workforce for a shorter time. Also, in the long run 
production losses affect the community's ability to maintain its level of provision of goods and services. ${ }^{13}$ This argument assumes, however, that the economy is operating at full employment levels. Obviously, this is not the case and consideration has to be given to the effect of unemployment levels ${ }^{14}$ on the value of increased output as a result of fewer lost working days. This point is noted and adjustment is made for the level of unemployment in the sensitivity analysis. The alternative outcome measure, namely, life years saved, is used because of the implication of different values attached to a year of life saved between, for example, socioeconomic groups or sex.

There is also discussion about what constitutes the social cost of smoking. Markandya and Pearce $^{8}$ list the types of cost that are widely considered to be constituent parts of the social cost of smoking, but also state that they cannot be added to produce a total, since some are relevant in some circumstances and some in others. In this study only those costs which are relevant to policy making within Wales are included, while others, such as health status of smokers and their relatives and friends and environmental factors are noted but not included as part of the appraisal.

\section{STAGES IN THE COST-BENEFIT ANALYSIS}

In undertaking these two studies, therefore, there are three basic stages. Firstly, the costs incurred in the intervention programme must be identified, measured, and assessed. Secondly, there is identification, measurement, and assessment of the benefits of the intervention, recognising the difficulties involved in attributing the outcomes to the particular input of HBW, and allowing for the timing of outcomes from the reduction in smoking prevalence. The third stage combines the cost and adjusted benefits and arrives at a measure of the net present value of the HBW no smoking intervention and the net cost per life year saved. It is accepted, however, that much of the data is rather 'soft'. Because of this a sensitivity analysis is included in the third stage to examine the impact of variations in the inputs and outcomes on the net present value.

\section{Costs of the intervention}

The no-smoking intervention of the HBW programme has resulted in costs being incurred by a range of organisations within the principality. The costs incurred by HBW itself are relatively easy to identify from the information systems of the Health Promotion Authority for Wales. Other participants, however, for example, the Welsh Office, health education and community nursing departments of district health authorities, general practitioners, district councils' environmental health officers, the voluntary sector, commerce and industry, and individuals, who have contributed directly or indirectly to the project can be identified. Consideration must therefore be given to any costs incurred by these organisations as a consequence of their contributions to $\mathrm{HBW}$ activities in general and the no-smoking intervention in particular.

In undertaking this task the various costs are grouped into three broad categories as follows:
(1) Direct cash costs. In this case the participant has made a direct cash outlay in pursuit of the objectives of the intervention. In general, because of the availability of costing systems in the organisations involved, these costs are the easiest to quantify objectively.

(2) Staff time. Health promotion is a labour intensive activity, and much of the no smoking intervention has required organisations to commit staff time to various activities. This staff time has a clear 'opportunity cost' for the organisation concerned and must therefore be counted as a cost of the intervention. However, in most organisations (particularly in the public sector) staff time recording systems are not sophisticated and we have usually had to rely on estimates of staff time utilisation produced by senior managers.

(3) Loss of utility. In some circumstances (particularly in the case of individuals or community groups), there has been a commitment of individual time to activities concerned with no smoking. This activity has been carried out in leisure time, and thus there is no opportunity cost in the sense of productive opportunities foregone. Nevertheless, it should be recognised that individuals have suffered a loss in utility through pursuing these activities. While noting the existence of this lost utility, it has not been quantified in this study.

Thus, the approach used to assess the costs of the no smoking programme is essentially a pragmatic one. Where costs can be estimated with reasonable objectivity, this has been done but in other cases the existence of such costs has merely been noted. A brief description of the main organisations that have incurred costs is given below, with a summary of costs shown in table II.

HEALTH PROMOTION AUTHORITY FOR WALES

For the years $1985-86$ and $1986-87$, the HBW programme was a discrete entity that came under the auspices of the University of Wales College of Medicine. Using available information for the period, estimates have been drawn up of the amount of resources that was committed to the no smoking intervention incorporating both direct costs (staff and consumables) and a proportion of the organisation's overheads. On 1 April 1987, the Health Promotion Authority for Wales was created as a statutory health authority and as such took over responsibility for the HBW programme, the Welsh AIDS campaign, and other health education activities.

\section{DISTRICT HEALTH EDUCATION DEPARTMENTS}

Since its inception in 1985, HBW has provided financial assistance to each of the nine district health education departments (DHED) in Wales to support a variety of locally managed programmes of health promotion.

In appraising the impact of the HBW interventions, it must be borne in mind that preventative activity in the no smoking field had been carried out by DHED staff for many years before the formation of $\mathrm{HBW}$. It is possible that some incremental activity was catalysed by the activities of $\mathrm{HBW}$, with consequent additional resource costs to the DHAs concerned. If so, then these additional costs should be attributed to the HBW intervention. In practice, however, it is not pos- 
sible to establish whether HBW resulted in the commitment of additional health authority resources to no smoking activity and hence no attempt has been made to assess any possible incremental costs.

\section{WELSH OFFICE}

Clearly the programme's main source of funding has been the finance it receives from the Welsh Office, and these costs have been dealt with above as costs of the Health Promotion Authority. In addition, however, there are the administration costs incurred by the Welsh Office. No information on these costs is available and so no provision can be made for this item. The absence of such a cost figure, as with others, will be dealt with via a sensitivity analysis.

\section{OTHER DISTRICT HEALTH AUTHORITY FUNCTIONS} A large number of health care professionals, such as medical staff, community nurses and physiotherapists employed by district health authorities are undoubtedly involved, in various ways, in attempting to deter smoking. There is a clear opportunity cost to the health authority and to the public sector at large associated with their involvement with the programme. There are, however, two practical problems associated with the assessment of these resource costs:

(1) As with district health education departments, it is not possible to separate the costs which have resulted from the HBW programme from those which were being incurred beforehand

(2) In practice there is no information about the no smoking activity of health care professionals working in district health authorities.

Hence, in carrying out a cost-benefit appraisal, no account has been taken of these costs, although it is recognised that they were incurred to some degree, and allowance is made for them in undertaking the sensitivity analysis.

\section{GENERAL PRACTITIONERS}

General practitioners in Wales spend part of their time in health promotion activities, including that of encouraging patients to stop smoking, and this is a relevant cost of the no smoking intervention. No information is available about the amount of time they spend giving advice on stopping smoking or the extent to which their pattern of activities has changed since the formation of HBW. With the introduction of the new GP contract which encourages the provision of specific health promotion sessions, better information may become available. The resource costs of GP's no smoking activities cannot currently be estimated but the existence of such a cost is noted and allowed for in the sensitivity analysis.

Table II Costs of no smoking programme $(£ 000)$

\begin{tabular}{|c|c|c|c|c|c|c|c|c|}
\hline \multirow[b]{2}{*}{ Cost centre } & \multicolumn{2}{|c|}{$1985-86$} & \multicolumn{2}{|c|}{$1986-87$} & \multicolumn{2}{|c|}{$1987-88$} & \multicolumn{2}{|c|}{$1988-89$} \\
\hline & $\overline{\text { Cash }}$ & Real & Cash & Real & $\bar{C}$ ash & Real & $\overline{\text { Cash }}$ & Real \\
\hline $\begin{array}{l}\text { Health promotion } \\
\text { authority } \\
\text { District health }\end{array}$ & 72 & 82 & 65 & 72 & 93 & 98 & 126 & 126 \\
\hline education departments & - & - & 17 & 19 & 24 & 25 & 41 & 41 \\
\hline NHS total & 72 & 82 & 82 & 91 & 117 & 123 & 167 & 167 \\
\hline Industry and commerce & - & - & - & - & 33 & 35 & 38 & 38 \\
\hline Total & 72 & 82 & 82 & 91 & 150 & 158 & 205 & 205 \\
\hline
\end{tabular}

The health service costs associated with the HBW no smoking programme (in both cash and updated to 1988 prices using the Retail Price Index) are summarised in table II.

\section{DISTRICT COUNCILS}

District councils in Wales have mainly been involved in the Heartbeat Award scheme. In this scheme, initiated by HBW, the district council makes an award to those catering establishments that meet certain 'health' criteria including the provision of no smoking areas. The scheme is administered by environmental health departments which link the scrutiny of potential applicants for the award with their normal day to day food hygiene responsibilities. Because little incremental resource cost was associated with this work nothing has been included in the statement of costs of the no smoking intervention.

\section{VOLUNTARY SECTOR}

The term voluntary sector includes a wide range of disparate organisations. During its life, HBW has worked with and through a variety of voluntary organisations according to the following classification:

(1) Health Related Organisations. These tend to be organised regionally and cover specialist areas. The main example of such a voluntary organisation in the no smoking field is Action on Smoking and Health (ASH) and HBW has had strong links with this organisation. Given that ASH is a specialist organisation in its own right, it does not seem likely that the activities of the HBW no smoking intervention have affected the costs incurred by ASH either way.

(2) Social welfare organisations. This category includes a wide range of organisations that might be regionally or locally organised and which undertake a variety of social welfare functions, for example, Citizen's Advice Bureaux, Shelter. There has been no specific involvement with these types of organisation in the no smoking field and hence there are no relevant costs for this exercise.

(3) Community organisations. These are small, locally based organisations that are both a part of the community and comprise members of the community, for example, Women's Institute, Lions, Round Table. HBW has had a considerable involvement with these organisations throughout Wales including aspects of no smoking. However, as all of this activity took place during the leisure time of those involved there was no opportunity cost of lost production.

\section{COMMERCE AND INDUSTRY}

The main resource commitment to health promotion by commerce and industry in Wales has been via the acquisition of 'Well Welsh' services of HBW. The aim of this service, which is paid for by commerce and industry, is to screen the workforce and to offer advice about promoting better health, including that of no smoking.

In addition to the costs of the screening itself, employing organisations will incur additional resource costs resulting from activities associated with the screening, such as administrative costs and loss of production. It is estimated that these costs will amount to $150 \%$ of the cost of the screening itself. 
Other costs associated with the 'Make Health Your Business Award' are not felt to be significant and are ignored for the purposes of this exercise.

\section{INDIVIDUALS}

Individuals who incurred costs can be classified as follows:

(1) Those who are themselves in the process of stopping smoking. There are two ways of looking at the costs involved in giving up smoking. On the one hand there will be a cash saving derived from not buying cigarettes or tobacco, while on the other, there may be cash payments for nicotine chewing gum and patches, hypnotherapy, sweets etc and loss of utility as a result of the loss of enjoyment of smoking tobacco.

(2) Those people who provide support to others who are quitting the smoking habit. There may be some loss of time as a consequence of the need to give emotional support to those attempting to give up smoking. It is virtually impossible, however, to identify, let alone quantify and evaluate these costs, and so their possible existence is noted only .

The sensitivity analysis compensates for some of the costs that have been identified above but not included in the analysis.

\section{Benefits of the intervention}

In identifying the benefits of a health promotion programme, it is assumed that the HBW intervention has acted as a prompt and trigger to those who are either contemplating stopping smoking or have started the process. The extent to which the HBW programme has contributed to the reduction in smoking in Wales is discussed later.

In identifying the benefits of a health promotion intervention, a distinction has to be made between intermediate and final outcomes. The intermediate outcomes of the programme are the reduction in the number of people who smoke and the amount of tobacco they consume plus some benefits which result directly from this, such as reductions in cleaning costs and in fire damage caused by smoking. More significantly, intermediate outcomes lead to a range of final outcomes, that will in turn result in a stream of benefits, as shown in the figure.

While the timing of intermediate outcomes, and of the benefits that flow directly from them is easy

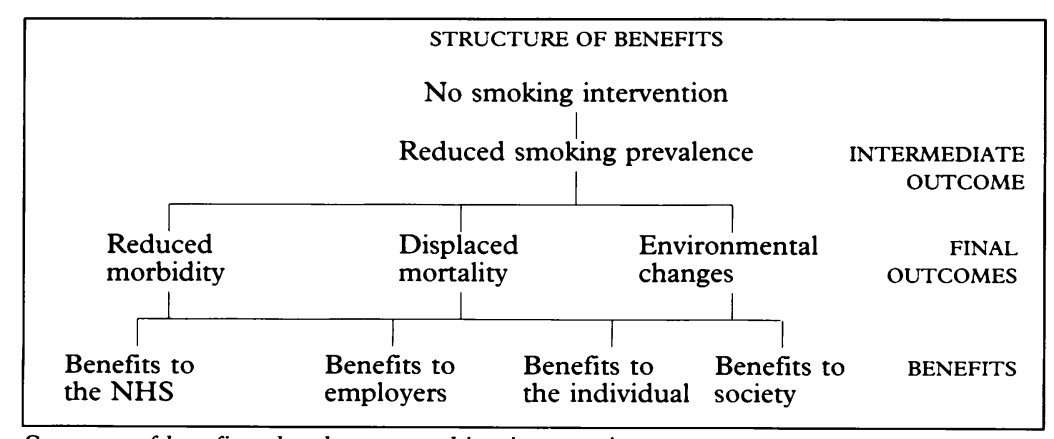

Structure of benefits related to no smoking intervention

Table III Timing profiles related to no smoking intervention

\begin{tabular}{llll}
\hline Disease type & $\begin{array}{l}\text { Reduced smoking } \\
\text { prevalence }\end{array}$ & $\begin{array}{l}\text { Benefits from } \\
\text { reduced morbidity }\end{array}$ & $\begin{array}{l}\text { Benefits from } \\
\text { displaced mortality }\end{array}$ \\
\hline Lung cancer & 1 & $8-12$ & $13-30$ \\
Coronary heart disease & 1 & $2-16$ & $17-30$ \\
Chronic bronchitis & 1 & $2-26$ & $27-30$ \\
\hline
\end{tabular}

to identify, the timing of final outcomes and of the benefits thus derived is much more complex. Although much medical evidence is available on the ultimate impact of smoking on morbidity, the timing of the onset of that morbidity is much less clear cut. The basic problem is that the precise physiological effects of smoking are not fully understood. It is not clear how soon after stopping smoking an individual benefits from the reduced risk of particular diseases, and consequently it is not clear how quickly benefits to society at large will accrue.

This study has concentrated on the impact of reduced smoking prevalence on three disease categories - coronary heart disease, lung cancer, and bronchial disease-in which smoking is a major contributory factor. For each specific disease category timing profiles have been applied as set out below.

\section{DISEASE CATEGORIES: BENEFIT TIMING PROFILES} Lung cancer

Most cases of lung cancer occur in the $45+$ years age group. Although the biochemical interactions involved are not fully understood, it is believed that stopping smoking at any time will reduce the ultimate risk of contracting lung cancer, although this process can take some time. It has been assumed that a period of seven years will elapse between reduced smoking prevalence and the benefits derived from reduced morbidity. Futhermore, since lung cancer generally leads to death within a few years of diagnosis it is assumed that the costs of lung cancer morbidity are incurred over a five year period. The costs of lung cancer mortality would only be incurred after this five year period of morbidity and hence only the benefits of displaced mortality from that point in time are counted.

\section{Coronary heart disease}

It is assumed that the benefits from reduced coronary heart disease morbidity start to be generated one year after the intermediate outcome has been achieved. We have also assumed that the costs of coronary heart disease morbidity are incurred for 15 years only, and that beyond this period death will have taken place. The benefits of displaced mortality have been included for the remainder of the appraisal period.

\section{Chronic bronchitis}

Again it is assumed that the benefits from reduced morbidity start to be generated one year after achievement of the intermediate outcome. Similarly, it is assumed that the benefits from reduced morbidity obtain for a 25 year period, with the benefits from displaced mortality obtaining for the balance of the appraisal period.

\section{WORKING LIFE YEARS LOST}

Applying these timing parameters to the first year of reduced smoking prevalence included in this study (1985-86) gives the picture shown in table III. Futhermore, health promotion, in common with most medical science, is not in the business of providing immortality. The best that can be done is to postpone death. The study therefore considers the impact of a reduced incidence of smoking upon working life years lost for each of the 
Table IV Annual savings to the NHS in Wales from changes in smoking related illnesses in Wales

\begin{tabular}{|c|c|c|c|c|}
\hline \multirow[b]{2}{*}{ Disease } & \multicolumn{2}{|c|}{ Cost of treatment $(£ m)$} & \multicolumn{2}{|c|}{ Annual saving $(£ 000)$} \\
\hline & $\overline{M e n}$ & Women & Men* & Woment \\
\hline Lung cancer & $3 \cdot 55$ & $0 \cdot 77$ & 44.375 & $5 \cdot 775$ \\
\hline Coronary heart disease & 1.92 & $1 \cdot 35$ & $24 \cdot 00$ & $10 \cdot 125$ \\
\hline Chronic bronchitis & $3 \cdot 71$ & $1 \cdot 38$ & $46 \cdot 375$ & $10 \cdot 350$ \\
\hline
\end{tabular}

^Based on an annual reduction in smoking in men in Wales of $1.25 \%$.

tBased on an annual reduction in smoking in women in Wales of $0.75 \%$.

Table $V$ Number of working days lost as a result of smoking related illnesses

\begin{tabular}{llrr}
\hline & \begin{tabular}{c} 
Attribution \\
\cline { 3 - 3 } Disease
\end{tabular} & \multicolumn{2}{c}{ No of working days lost } \\
\cline { 3 - 4 } factor (\%) & \multicolumn{1}{c}{ Men } & Women \\
\hline Lung cancer & $75 \cdot 9$ & 16433 & 1423 \\
Coronary heart disease & $20 \cdot 0$ & 590000 & 53000 \\
Chronic bronchitis & $68 \cdot 4$ & 490360 & 50172 \\
\hline
\end{tabular}

three disease categories. (The existence of nonworking life years lost are noted but not included as part of the investigation.)

\section{BENEFITS NOT RELATED TO HEALTH}

Other benefits from a reduction in smoking that are not related to health are as follow:

(1) Reduction in fires caused by smoking;

(2) Reduction in damage and destruction caused by fires resulting from smoking;

(3) Increased personal comfort as a result of a smoke free environment;

(4) Contribution to 'cleaning up' the environment;

(5) Reduction in deaths and disability as a result of passive smoking.

However, this study concentrates on the impact of the decline in smoking prevalence on reduced morvidity and displaced mortality, and other factors are allowed for in the sensitivity analysis, where the magnitude of benefits generated by the programme are reduced by up to $20 \%$.

\section{REDUCED MORBIDITY}

There are four recipients of benefits - the NHS, commerce and industry, the individual, and society as a whole. In this study the benefits to the individual and society have not been included but their existence is noted and they are recognised as being very relevant to any discussions of the relative worth of health promotion programmes.

\section{Benefits to the NHS}

No precise data on the costs and potential cost savings to the NHS of smoking related illnesses and disabilities exist, although it has been estimated that the annual cost of smoking to hospitals is $\AA^{351}$ million (at 1990-91 prices). ${ }^{15} \mathrm{We}$ have adapted the findings of Cohen ${ }^{16}$ to arrive at the total costs of treating lung cancer, coronary heart disease, and chronic bronchitis/emphysema as a result of smoking in Wales. The savings and benefits to the NHS can be calculated by multiplying the percentage reduction in smoking prevalence by the costs of treating the three disease groups as a result of smoking. Table IV indicates the extent of savings to the NHS from changes in smoking related illnesses within Wales.

Table VI Reduction in lost output (1988 prices)

\begin{tabular}{llll}
\hline Disease & $\begin{array}{l}\text { Reduction in } \\
\text { working days lost } \\
(\text { no) }\end{array}$ & $\begin{array}{l}\text { Gross cost of } \\
\text { employment } \\
(£)\end{array}$ & $\begin{array}{l}\text { Value of } \\
\text { output not lost } \\
(£)\end{array}$ \\
\hline Lung cancer & 216 & $56 \cdot 20$ & 12139 \\
Coronary heart disease & 7773 & $56 \cdot 20$ & 436842 \\
Chronic bronchitis & 6506 & $56 \cdot 20$ & 365637 \\
\hline
\end{tabular}

Benefits to commerce and industry

The illnesses and disabilities caused by smoking also impose costs on industry and the economy in the form of lost output because of sickness absence from work. Estimates of the cost to the UK economy of lost output resulting from smoking related illnesses range from nearly 16 million working days ${ }^{16}$ to 50 million working days. ${ }^{17}$ In this study we consider the number of working days lost through sickness absence (as represented by official sickness absence statistics) in Wales by each disease group. We recognise that this approach may understate the extent of the problem, since GP's certificates do not fully indicate the degree of sickness absence from work.

We use attribution factors to estimate the extent to which this certified incapacity can be attributed to smoking. These are based on 'avoidable life years lost' and are therefore mortality rather than morbidity related. The attribution factors used are the most conservative of those quoted in an ASH report $^{18}$ and a study in the USA by Almer and Dull, ${ }^{19}$ which was applied to English and Welsh data by Godfrey, Hardman, and Maynard. ${ }^{20}$ Using the attribution factors in each of the disease groups it is possible to determine the number of working days lost as a result of smoking, as shown in table $\mathrm{V}$.

The benefit to industry and the economy from a reduction in sickness absence caused by smoking related illnesses and disabilities is obtained by multiplying the percentage reduction in smoking prevalence by the number of working days lost through smoking related problems. The value of the output that would no longer be lost to the economy is arrived at by multiplying the number of working days no longer lost by the gross cost of employment (including wages, employers' national insurance contributions, etc) and the results can be seen in table VI.

\section{DISPLACED MORTALITY}

The Royal College of Physicians ${ }^{17}$ estimated that the total number of premature deaths as a result of smoking was 50000 while Cohen ${ }^{16}$ estimated the number to be over 79000 . Therefore any reduction in mortality rates will mean that the number of life years lost prematurely will be reduced. The impact of this reduction will produce benefits for the NHS, for industry and the economy, and for individuals and society as a whole, although only the first two recipients will be considered in the measurement and valuation process.

\section{Benefits to the NHS}

The reduction in premature deaths is not the only aim of a health promotion programme: it also seeks to increase the quantity and quality of life. Reductions in premature deaths will not necessarily result in increased health care costs in the future. Improvements in lifestyle achieved through reduced smoking may, however, reduce disease and disability in the elderly. This will place fewer demands on the health services and release resources for other health needs. In addition, a reduction in premature deaths will provide benefits to the NHS through reductions in the loss of NHS employees and their associated skills and experience. 
Table VII Years of working life lost as a result of smoking in Wales (1987)

\begin{tabular}{lll}
\hline & \multicolumn{2}{c}{ Years lost $(000)$} \\
\cline { 2 - 3 } Disease & Men & Women \\
\hline Lung cancer & 1.97 & 0.91 \\
Coronary heart disease & 2.42 & 0.58 \\
Chronic bronchitis & 0.64 & 0.22 \\
\hline
\end{tabular}

Benefits to commerce and industry

Premature death means a loss of potential working life years and their associated output. Utilising the attribution factors, it is possible to determine the years of working life lost as result of smoking, as shown in table VII

In addition, the value of output lost as a result of premature mortality can be calculated by multiplying the resultant number of working life years lost through smoking by the average output per head, $£ 8208$ per annum (1988 prices), (albeit a crude indicator across occupational groups and skill areas). These amounts, when multiplied by the decline in smoking, produce the value of output 'saved'. The results can be seen in table VIII.

Another consequence of displacing mortality is an increase in the supply of labour and in the number of retired people. The effect of this increase in the supply of labour is dependent upon levels of unemployment. For example, Williams ${ }^{14}$ disregarded increases in production associated with employment gains because of the level of unemployment. There is no UK study to indicate the effects of such an increase in the labour supply, however, and since demographic changes have been cited as causing a potential shortage of appropriate labour in the future, the reduction in premature mortality may prove to be a benefit rather than a problem to industry and commerce.

Whatever the impact of the reduction in working life years lost on the supply of labour, a conservative view is adopted and the stream of benefits generated is reduced by up to $20 \%$ in the sensitivity analysis to compensate for any negative effects resulting from unemployment levels and excess labour supply.

\section{The evaluation}

This section incorporates the costs and benefits in an overall evaluation of the no smoking intervention of the HBW programme. The net present value of the intervention and the net costs per life year saved are calculated, making different assumptions about the extent to which the benefits

Table VIII Value of output 'lost' through premature mortality and 'saved' as the result of the decline in smoking (1988 prices)

\begin{tabular}{|c|c|c|c|c|}
\hline \multirow[b]{2}{*}{ Disease } & \multicolumn{2}{|c|}{ Value of output lost $(£ m)$} & \multicolumn{2}{|c|}{ Value of output saved $(£ 000$} \\
\hline & $\overline{M e n}$ & Women & $\overline{\mathrm{Men}}$ & Women \\
\hline $\begin{array}{l}\text { Lung cancer } \\
\text { Coronary heart disease } \\
\text { Chronic bronchitis }\end{array}$ & $\begin{array}{r}16 \cdot 17 \\
19 \cdot 86 \\
5 \cdot 25\end{array}$ & $\begin{array}{l}7 \cdot 47 \\
4 \cdot 76 \\
1 \cdot 81\end{array}$ & $\begin{array}{r}202 \cdot 10 \\
248 \cdot 25 \\
65 \cdot 63\end{array}$ & $\begin{array}{l}56 \cdot 00 \\
35 \cdot 70 \\
13 \cdot 58\end{array}$ \\
\hline
\end{tabular}

Table IX Net present values and net cost per working life saved of HBW programme

\begin{tabular}{llcc}
\hline Appraisal & $\begin{array}{l}\text { Present value of costs } \\
(£ 000)\end{array}$ & $\begin{array}{l}\text { Present value of benefits } \\
(£ 000)\end{array}$ & $\begin{array}{l}\text { Net present value } \\
(£ 000)\end{array}$ \\
\hline NHS & 394 & 4134 & 3740 \\
Economic & 394 & 43503 & 43109 \\
Total cost of programme $£^{536000}$ & & \\
Working life year saved $92779 \cdot 1$ & & \\
Cost per working life year saved $£ 5 \cdot 78$ & & \\
\hline
\end{tabular}

can be attributed to the HBW programme itself rather than other factors. The analysis is conducted on two separate bases-a health service appraisal and an economic appraisal-and, recognising the political importance of achieving a relatively short term repayment period on such a project, the payback period is also calculated. Finally, because much of our data is 'soft' a sensitivity analysis is carried out on the results.

Using the data on costs and benefits and applying the timing factors referred to below, standard discounting techniques are used to compute net present values for both the appraisals. In undertaking this exercise, the following three factors have been applied:

(1) A discount rate of $6 \%$ has been used. This was the official test discount rate recommended by the Treasury as the social opportunity cost rate at the time of the study. This rate was the marginal rate of return on private sector investment and represented the opportunity cost of public sector investment;

(2) The benefits have been included up to the year 2016, 30 years from the start of the HBW programme. Although benefits will undoubtedly accrue beyond that date, they will not materially affect the overall present value of the project;

(3) All costs have been expressed in terms of mid- 1988 prices and all benefits are computed at 1988 price levels.

\section{Impact of $\mathrm{HBW}$}

Combining the costs of the HBW programme with the discounted benefits gives us the net present values for the health service and economic appraisals, while combining the costs of the programme with the number of working life years saved produces the net costs per life year saved. Those are given in table IX.

We believe that this analysis indicates, in a reasonably robust manner, that the benefits from reduced smoking prevalence in Wales greatly exceed the costs of the HBW no smoking intervention. It is, however, far more difficult to prove that the reductions in smoking (and the benefits) are directly caused, in whole or in part, by the HBW programme. Because many of the innovative ideas in health promotion developed by HBW have been picked up and initiated in various parts of England it has not been possible to find a suitable control area for comparison. An analysis has therefore been performed of the net present value of the project for different impact rates. Impact rates are the proportion of total benefits that can be attributed to the HBW intervention. The resulting net present values and the net costs per working life year saved are shown in table X.

It can be seen that with an impact rate of $10 \%$, the HBW intervention still gives a small net present value to the NHS in Wales and a larger net present value to the Welsh economy at large, and the net costs per working life year saved compare favourably with other health care interventions.

\section{Sensitivity analysis}

No attempt has been made to disguise the lack of information needed for a definitive cost-benefit appraisal of the no smoking intervention. The 
major gaps in the data set are highlighted in table $\mathrm{XI}$. It is also recognised that much of the available information used in this study is 'soft'. Various forms of sensitivity analysis have been undertaken to identify the robustness of the calculations.

Clearly, the costs of the HBW no smoking intervention are dwarfed by the value of the benefits generated. Consequently, the results of

Table $X$ Net present value (NPV) of the $H B W$ no smoking project in relation to different impact rates

\begin{tabular}{|c|c|c|}
\hline Impact rate $(\%)$ & NPV to NHS (£000) & NPV to economy (fO00) \\
\hline $\begin{array}{l}100 \\
50 \\
25 \\
10\end{array}$ & $\begin{array}{r}3740 \\
1673 \\
640 \\
19\end{array}$ & $\begin{array}{r}43109 \\
21358 \\
10482 \\
3956\end{array}$ \\
\hline \multicolumn{3}{|l|}{ Net cost per working life year saved } \\
\hline $\begin{array}{l}\text { Working life years lost } \\
\text { Net cost per working life year saved }\end{array}$ & & $\begin{array}{l}92776 \cdot 1 \\
£ 5 \cdot 78\end{array}$ \\
\hline $\begin{array}{l}\text { At a } 50 \% \text { impact rate: } \\
\text { Working life years lost }\end{array}$ & & $46388 \cdot 05$ \\
\hline At a $25 \%$ impact rate: & & \\
\hline $\begin{array}{l}\text { Working life years lost } \\
\text { Net cost per working life year saved }\end{array}$ & & $\begin{array}{l}23194 \\
£ 23 \cdot 11\end{array}$ \\
\hline At a $10 \%$ impact rate & & \\
\hline $\begin{array}{l}\text { Working life years lost } \\
\text { Net cost per working life year saved }\end{array}$ & & $\begin{array}{l}9277 \cdot 61 \\
\times 57 \cdot 78\end{array}$ \\
\hline
\end{tabular}

Table XI Costs and benefits of no smoking intervention that were not included in the appraisal

Missing costs:

Internal Welsh Office costs (associated with HBW)

District health authority costs (associated with HBW)

Gistrict health authority costs (associated with HBW

Any additional costs to the NHS caused by the displacement of mortality to older age groups

Missing benefits:

Reduction in the incidence of damage and death caused through smoking related fires

Reduced building cleaning costs

Reductions in mortality/morbidity from causes other than lung cancer, coronary heart disease and bronchial disease (for example, fire related deaths)

Life years saved after retirement

Table XII Results of sensitivity analysis

\begin{tabular}{|c|c|c|}
\hline \multirow[b]{2}{*}{ Impact rates and variations } & \multicolumn{2}{|c|}{ Net present value $(\mathbb{Z}, 000)$} \\
\hline & To NHS & To economy \\
\hline Result impact of $100 \%$ & 3740 & 43109 \\
\hline $\begin{array}{l}\text { Variations: } \\
10 \% \text { benefit reduction } \\
20 \% \text { benefit reduction } \\
5 \text { year delay in receipt } \\
10 \% \text { reduction plus } 5 \text { year delay }\end{array}$ & $\begin{array}{l}3327 \\
2914 \\
2607 \\
2307\end{array}$ & $\begin{array}{l}38795 \\
34409 \\
29795 \\
26744\end{array}$ \\
\hline $\begin{array}{l}\text { Result at impact rate of } 50 \% \\
\text { Variations: }\end{array}$ & 1673 & 21358 \\
\hline $\begin{array}{l}10 \% \text { benefit reduction } \\
20 \% \text { benefit reduction } \\
5 \text { year delay in receipt } \\
10 \% \text { reduction plus } 5 \text { year delay }\end{array}$ & $\begin{array}{r}1466 \\
1260 \\
1106 \\
956\end{array}$ & $\begin{array}{ll}19 & 182 \\
17 & 008 \\
14 & 683 \\
13 & 175\end{array}$ \\
\hline $\begin{array}{l}\text { Result at impact rate of } 25 \% \\
\text { Variations: }\end{array}$ & 640 & 10482 \\
\hline $\begin{array}{l}10 \% \text { benefit reduction } \\
20 \% \text { benefit reduction } \\
5 \text { year delay in receipt } \\
10 \% \text { reduction plus } 5 \text { year delay }\end{array}$ & $\begin{array}{l}537 \\
434 \\
356 \\
281\end{array}$ & $\begin{array}{l}9394 \\
8306 \\
7144 \\
6390\end{array}$ \\
\hline $\begin{array}{l}\text { Result at impact rate of } 10 \% \\
\text { Variations: }\end{array}$ & 19 & 3956 \\
\hline $\begin{array}{l}10 \% \text { benefit reduction } \\
20 \% \text { benefit reduction } \\
5 \text { year delay in receipt } \\
10 \% \text { reduction plus } 5 \text { year delay }\end{array}$ & $\begin{array}{r}-22 \\
-63 \\
-94 \\
-124\end{array}$ & $\begin{array}{l}3521 \\
3086 \\
2921 \\
2620\end{array}$ \\
\hline $\begin{array}{l}\text { Sensitivity analysis of working life years } \\
\text { At } 100 \% \text { impact rate: } \\
\text { Working life years lost } \\
\text { Net cost per working life year saved }\end{array}$ & & $\begin{array}{c}83498 \cdot 5 \\
£ 6.42\end{array}$ \\
\hline $\begin{array}{l}\text { At } 50 \% \text { impact rate: } \\
\text { Working life years lost } \\
\text { Net cost per working life year saved }\end{array}$ & & $\begin{array}{l}41749 \cdot 97 \\
\{12 \cdot 84\end{array}$ \\
\hline $\begin{array}{l}\text { At } 25 \% \text { impact rate: } \\
\text { Working life years lost } \\
\text { Net cost per working life year saved }\end{array}$ & & $\begin{array}{l}20874 \cdot 6 \\
£ 25 \cdot 68\end{array}$ \\
\hline $\begin{array}{l}\text { At } 10 \% \text { impact rate: } \\
\text { Working life years lost } \\
\text { Net cost per working life year saved }\end{array}$ & & $\begin{array}{l}8349 \cdot 85 \\
£ 64 \cdot 19\end{array}$ \\
\hline
\end{tabular}

the cost-benefit analysis show very little sensitivity to variations in the levels of cost incurred. We have therefore concentrated on the impact of variations in the size and timing of benefits on the net present values. For each impact rate, the following variations have been made and the effect on net present values assessed:

(1) Reduce overall benefit levels by $10 \%$;

(2) Reduce overall benefit levels by $25 \%$ including effects of unemployment;

(3) Delay receipt of all benefits by an additional five years;

(4) Reduce benefit levels by $10 \%$ plus delay of five years (that is (1)+(3));

(5) Reduce working life years saved by $10 \%$. The results are shown in table XII.

It can be seen that at all impact rates and for all variations the net present value of the economic appraisal always remains positive. The health service appraisal gives positive net present values for all variations and all impact rates with the exception of the $10 \%$ impact rate where reductions in benefit levels or timing delays, or both, will result in negative net present values. Similarly the net cost per working life year saved shows the relative efficiency of the programme compared with others listed in 'QALY' (quality adjusted life years) league tables, ${ }^{1421}$ despite only including working life years, rather than all life years, in the calculation. Obviously, some adjustment would have to be made to equate life years with QALYs, but the sensitivity analysis has reduced the number of working life years saved by $10 \%$.

\section{Conclusion}

This study aimed to assess the costs and benefits associated with a health promotion campaign designed to reduce the incidence of smoking, using the HBW no smoking programme for this purpose.

Two perspectives have been taken. The first limits itself to the overall impact of the no smoking intervention on public expenditure on the NHS within Wales. The second perspective considers the impact of the intervention on the Welsh economy at large. Both evaluations are restricted to Wales, however, and do no consider the impact of the intervention on other parts of the UK. Given this emphasis, this study should be seen as a basis for making policy decisions within Wales.

The cost-benefit analysis, on both evaluation bases, showed that the HBW programme generates positive net present values even at impact rates as low as $10 \%$. Similarly, the net cost per working life year saved at this impact rate works out at approximately $£ 64$.

Although we do not have the information available to prove that the HBW intervention is the causal factor in achieving reduced smoking prevalence in Wales, what information is available suggests that HBW has been a significant factor.

It is recognised that not all of the potential costs and benefits have been measured and valued and there may be other costs and benefits which have not even been considered. The sensitivity analysis has made some allowance for these deficiencies, however, and has shown that the results of the evaluations are quite robust. 
What can be stated confidently is that programmes designed to reduce smoking are extremely worthwhile-economically, financially, and for many other reasons. In terms of future policy directions in Wales, even if $\mathrm{HBW}$ were responsible for only $10 \%$ of the decline in smoking prevalence, there would still have been a surplus. The programme has been a successful and 'profitable' investment of public funds, with the net cost of a working life year saved comparing favourably with other alternatives, for example GP consultations. ${ }^{1422}$

This study does not, however, consider the efficiency of the HBW programme in relation to other ways of reducing smoking. Taxation and restraints on the advertising of tobacco products, among others, have been advocated as means of reducing smoking and generating the benefits identified in this study. While there is evidence to support the view that programmes such as that of HBW can be effective in preventing people from starting to smoke and in helping smokers to give $\mathrm{up}^{23}$ as well as reducing the consumption of tobacco, ${ }^{10}$ Townsend ${ }^{9}$ suggests that increasing tobacco prices by $20 \%$, alongside other approaches, would lead to a $20 \%$ fall in consumption. The determination of the relative efficiency of the approaches to reducing smoking prevalence is an area requiring further investigation.

Futhermore, this study does not show the merits of health promotion per se. The HBW programme was multifaceted, covering nutrition, physical exercise, and smoking, among other aspects. To make informed choices about the allocation of resources to health promotion interventions, similar studies must be undertaken of these other activities.

We also argue that similar approaches to economic evaluation should be applied to all aspects of health investment. The recently introduced NHS reforms require health care purchasers to assess priorities and choose between competing areas of activity as a means of improving the health status of the population. Purchasers will thus require information on the economic return from investments in curative, caring, and preventive/ promotion services, as well as the individual components making up each of these three groups.
The results of studies such as this one should help inform purchasers about the relative balance between different approaches to health investment.

This article is based on a research report published by the Health Promotion Authority for Wales. This report was compiled by Don Nutbeam, who at the time was Assistant Director of HPAW (Research), Malcolm Prowle, who was Assistant Director of (Research), Malcolm Prowle, who was Assistant Director
HPAW (Development and Resources) and Ceri Phillips.

1 Jones L, Baker MR. The application of health economics to health promotion. Community Medicine 1986; 8: 224-9.

2 Cribb A, Haycox A. Economic analysis in the evaluation of health promotion. Community Medicine 1989; 11:299-305.

Engleman SR, Forbes JF. Economic aspects of health education. Soc Sci Mled 1986; 22: 443-58.

4 Raw M. Helping smokers stop. Copenhagen/London: World Health Organisation/British Medical Association, 1988.

5 Nutbeam D. Planning for a smoke-free generation. Copenhagen/London: World Health Organisation/British Copenhagen/London: World
Medical Association, 1988.

6 Welsh Heart Planning Directorate. Take heart: a consultative document on community based heart healthy initiatices in W'ales. Cardiff: Heartbeat Wales, 1985.

7 Drummond MF, Ludbrook A, Lowson K, Steele A. Studie. in economic appraisal in health care Vol 2. Oxford: Oxford University Press, 1986.

8 Markandya A, Pearce DW. The social costs of tobacco smoking. $\mathrm{Br}$ f Addic 1989; 84: 1139-50.

9 Townsend JL. Cigarette Tax, Economic welfare and social class patterns of smoking. Applied Economics 1987; 19. 355-65.

10 Maynard A. Economic aspects of addiction policy. Health Promotion 1986; 1: 61-71.

11 St Leger AS. Would a healthier population consume fewer health service resources? Int $\mathcal{F}$ Epidemiol 1989; 18: 227-31.

2 Leu RE, Schaub T. Does smoking increase medical care expenditure? Soc Sii Med 1983; 17: 1907-14.

13 Drummond MF, Ludbrook A, Lowson K, Steele A. Studies in economic appraisal in health care. Vol 2. Oxford: Oxford University Press, 1986: 13.

14 Williams A. Economics of coronary artery bypass grafting. BMIf 1985; 291: 326-9.

5 Mawhinney B. Parliamentary written answer. House of Commons Official Report (Hansard) 1993 March 3: col 167.

16 Cohen DR. Economic consequences of a non-smoking generation. Aberdeen: University of Aberdeen, Health Economics Research Unit, 1984. Discussion paper 06/84.

17 Royal College of Physicians. Smoking or Health. London: Pitman Medical, 1977.

18 ASH. Smoking statistics. London : ASH, 1989. Factsheet no 1

19 Almer RW, Doll HB, eds. Closing the gap: the burden of unnecessary illness. Oxford: Oxford University Press, 1987.

20 Godfrey C, Hardman G, Maynard A. Priorities for health promotion. York: Centre for Health Economics, University promotion. York: Centre for Health Econ

21 Bryan S, Parkin D, Donaldson C. Chiropody and the QALY: a case study in assigning categories of disability and distress to patients. Health Policy 1991; 18: 169-85.

22 Scott T, Maynard A. Will the new GP contract lead to cost Scott T, Maynard A. Will the new GP contract lead to cost
effective medical practice? York: Centre for Health Economics, University of York, 1991. Discussion paper no

23 Catford JC, Nutbeam D, Woolaway MC. Effectiveness and cost-benefits of smoking education. Commenity Medicine $1984 ; 6$ : $264-72$. 